\title{
Integration of SCOR-Modeling and Logistical Concept of Management in the System of Internal Transportation of Milk Cooperative
}

\author{
Oleksandr Velychko
}

PhD in Economics, Associated Professor, Head of Management and Law Department, Dnipropetrovsk State Agrarian and Economic University, Ukraine, Voroshylova Street 25, Dnipropetrovsk, Ukraine, 49600

Email: olvel@ukr.net

\section{Doi:10.5901/mjss.2015.v6n1s2p14}

\begin{abstract}
Features of combined application of concepts/technologies of SCOR-modeling with logistical concept/technology of management of a separate link in a chain of supply in the milk business have been studied in the article. The term has been introduced and the essence has been provided of the private-cooperative, cooperative and mixed supply chain. The link of the cooperative supply chain "milk producer - serving cooperative" in the system of SCOR-model. Attention has been focused on rationalistic type of logistics as a base of logistical concept/technology for optimization of business processes in the system of SCM. Mechanism and methodology of logistical optimization of internal transportation in the milk serving cooperative has been added focused on metrics of SCOR-model. Integrated application of SCOR-modeling has been suggested along with the method of linear programming on stages of creation (projecting) and functioning of the milk cooperative. Methods of formation of restrictions of mathematical model concerning possible negative effect from using additional points of milk gathering by cooperative through the mechanism of planning progressiveness (digressiveness) of additional transportation costs have been studied. Expediency of using in limited models both individualized or exact and averaged and wide-band parameters corresponding to factors of significant and insignificant influence on effectiveness of cooperative activity has been defined. Conditions of application of the developed methods and models for the level of planning with horizon moderate precision have been grounded.
\end{abstract}

Keywords: SCOR-model, logistics, integration, supply chain, transportation, milk cooperative, optimization, methods.

\section{Introduction}

Modern agrarian cooperation plays a significant economic and social role in the support of development of agrarian business and rural areas. At that cooperative forms of business operation remain rather complex objects of management. They include serving logistical-marketing cooperatives of stocking and distribution of milk raw materials.

The complexity of managing such organizations is caused not only by the nature of cooperative management but also by features of the milk business. Such features are, for example, presence of a large number of small-volume producers, significant dispersion of members of producing cooperatives on rural areas, impossibility of long-term storing of the produce, existence of conditions similar to the market of pure competitiveness and so on.

At that modern milk-serving cooperative in most are multifunctional and provide their milk produce members with a wide range of extra services besides stocking-distributional services.

Those and other features make adequate management really essential, which should be oriented on rational use of the existing potential and limited nature of resources. In this case rational organization of internal transportation of milk raw materials within the cooperative is a prioritized task.

This process is a constituent part of a general supply chain in milk business and to manage it different concepts/technologies which are used in SCM system can be applied. At that integration of different approaches to planning managerial decisions in the field of servicing cooperation might be effective.

One of the most prospective directions of integrated application in the cooperative milk business might be complex concepts/technologies of SCOR-modeling system (Supply Chain Operations Reference model) and logistical concepts/technologies of management. Such complementarity enables us to increase the level of all-inclusiveness and reasonableness of prepared decisions for complex objects of management. 


\section{Literature Review}

The problem of managing the supply chain using SCOR-model or its separate elements in agribusiness has been studied by such scientists as L. Aramyan (2006), Li Dong (1999), L. Li (2011), M. Moazzam (2012) and others.

The implementation of logistical concept in management of the milk chain and stocking-distributing cooperatives at the market of milk has become a subject of attention by A. Krievin (2010), N. Shadbolt (2009), M. Sharm (2008), M. Tariq (2008), D. Vaněček (2006), U. Zia (2009) and others.

At the same time the profound studies of methodology of logistical optimization in transportation of the milk business and in particular in its cooperative sector have been carried out by G. Claassen (2007), T.G. Crainic (2013), I. Dayarian (2014), T. Du (2007), A.E. Dooley (2005), A. Hoff (2007), Hui Juan Ma (2012), M. Jafari-Eskandari (2010), N. Lahrichi (2012), D.S. Lobo (2004), R.S. Martins (2004), S.J. Sadjadi (2009) and others.

At that M. Moazzam (2012), E. Garnevska (2012) and N.E. Marr (2012) have suggested the integration of the corresponding quality measures of food produce in accordance with the corresponding metrics of the SCOR-model. They implemented the benchmarking and studied the best practices in managing of the milk chain in different countries as well as features of its adaptation to local conditions. D. Vaněček (2006) and R. Toušek, (2006) have studied the solution to the problem of increasing competitiveness of participants in the milk chain through active use of the logistical outsourcing in the system of SCM concept.

M. Jafari-Eskandari (2010) and other researchers have suggested a general algorithm which enables scientists to define optimal routes of transportation of milk and to minimize transportation costs of milk in conditions of uncertainty. The realization of the algorithm is based on the method of linear optimization.

Researchers by R. S. Martins $(2003,2004)$ and other scientists are oriented directly on logistical optimization of the process of milk gathering in the system of the agrarian serving cooperation. The authors have developed the models which unlike other solutions to transportation tasks in urban areas, consider in great detail features of gathering and transporting milk in rural areas. At that scientists have been offered the methods which consider certain limitations of access to each farm, depending upon capabilities of the transportation vehicles to carry out collection of milk in those areas.

In most recent studies N. Lahrichi (2013) and other scientists have developed a model of the transportation task based on analyses of scenarios for optimization of routes of milk gathering from farms and its supply to milk processing enterprises.

In the dissertation research I. Dayarian (2014) has suggested two variants of a tactical plan of routing for the activity of collecting milk from producing enterprises. At that I variant is connected with the level of planning at the fixed level of milk production in a certain period, and II variant is a more precise plan and considers potential changes of such sizes.

Along with that in the existing researches not sufficient attention is paid to the essence of types of supply chain in the milk business from the position of features of its control.

The process of integrated use of concepts/technologies of SCOR-modeling with logistical concept/technology of management requires further research.

Attention is not accentuated on the rationalistic type of logistics as a basis of logistical concept/technology of management.

Differentiation of models of optimization of internal transportation for the stage of creation (organization) and stages of functioning of the milk serving cooperative is not used.

Limitation of optimization model does not include the condition of the long progressive character of variable transportation costs, and vice versa digressive character of milk stocking might lead to critically high prices for services for members of the serving cooperative.

At that most models are oriented on general algorithm of the approach to optimization or on very complex systems which consider many detailed but not always predicted and essential factors for projecting or even current functioning of the effectively functioning milk cooperative.

\section{Purpose, Materials and Methods of Research}

The purpose of the research is to find ways of further development of theory of integrated (combined) application of concepts/technologies of SCOR-modeling with logistical concept/technology of management in the milk supply chain and to improve and expand the mechanism and methodology of logistical optimization of the business process "internal transportation" of the milk cooperative based on metrics of the SCOR-model. 
Materials for the research were reference-informative data and scientific publications on the problem of SCORmodeling and logistical management of the system of collecting and internal transportation of milk raw materials in the cooperative supply chain as well as empiric data concerning the activity of separate milk serving cooperatives.

Methodological basis of the research has been a combined use of principles of rationalistic logistics, concept/technology of SCOR-modeling as well as the method of linear programming (logistical-transportation task and the task of a commercial traveller).

\section{Results and Discussions}

SCOR-model was developed and is still being developed by Supply Chain Council (SCC) as an inter-branch standard for supply chain management. SCOR-model unites three modern managing concepts/technologies: re-engineering of business processes, benchmarking and application of the best practiced (Supply Chain Council [SCC], 2012).

It is essential but one of the approaches and instruments for effective supply chain management.

We believe that in many cases the process of SCOR-modeling is reasonable to carry out in the integrated way along with logistical concept/technology of management as a rationalistic type of modern entrepreneurial logistics.

Besides it is essential while projecting, integration and optimization of certain business processes in a cooperative milk chain. There logistical concept/technology may create the support of realization of SCOR-modeling at its II level (planning, carrying out and process provision), as well as - III levels (flows, elements and course of the process).

Modern entrepreneurial logistics has two main evolutionary directions of development: rationalistic type (scientific principles and methodology of optimization of commercial business activity and support of decisions in the system of management) and provisional type (process of providing main business and different logistical formations connected with them) (Velychko, 2014).

Logistical concept of management is mainly based on basics of rationalistic logistics and it is the approach to management, but it is not its object, unlike management of logistics (provisional type). Besides SCM and entrepreneurial logistics have only partly common base (in the part of the integrated logistics). Provisional business logistics is oriented only on the part of the material flow, while the concept of SCM includes all material flow.

At that the principle of rationalism is more naturally manifested in the essence and fundamental basis of entrepreneurial logistics rather than in the concept of supply chain management, which key basis is a principle of systematic integration.

The basis of the author's research is the rationalistic type of entrepreneurial logistics as one of the ways and instruments of optimizing phenomena in economics in particular in supply chain management. The rationalistic type of entrepreneurial logistics is a certain development of mathematical logistics as a science on features and methods of thinking and part of military logistics (rational organization of transportation and supply of troops).

Classical mathematical logistics has not lost its connection to economical processes even nowadays. It has become a tangent to business logistics, first of all due to ways of economical mathematical modeling with the method of linear programming which plays a significant role. Thus linear programming is one of the ways of implementing logistical concept in the system of management.

In the whole world the most widespread forms of operating agrarian entrepreneurship is a private-corporative form and a cooperative form.

On their basis two main models of supply chain are formed in agribusiness: private-corporative and cooperative.

Thus there are successive stages of supply in private-corporative chain; supply of production and distribution are located within the control of one person or a few people, in cooperative - it is controlled through democratic management and multi-personal equitable joint ownership, mainly on a non-profit basis. The purpose of the first one is maximization of private-corporative financial results while that of the latter - minimization of logistical expenses and increase of profits of cooperative owners (members).

Generally SCOR-model is oriented on the chain with main links such as a focus company, its suppliers and consumers as well as suppliers of suppliers and consumers of consumers.

In our opinion in cooperative milk chain these links are represented correspondingly by a milk-processing factory, milk serving cooperative, distributive center, producers of milk raw materials and retailing network.

At that separate links of such a chain might have corporative nature. Then we might speak about a mixed supply chain (with the feature of its control).

Internal transportation of the milk cooperative with the object of SCOR-modeling and logistical optimization at the level "supplier of a supplier-supplier" or "producers or milk raw materials - milk serving cooperative" (Figure 1). 


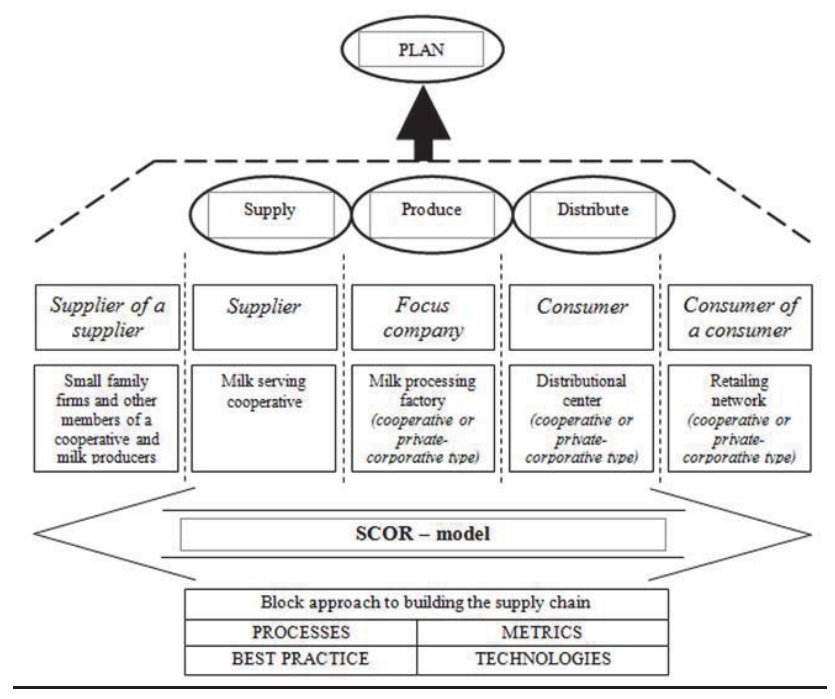

Figure 1: Generalized type of the SCOR-model of a cooperative milk chain Source: developed by the author based on (SCC, 2012)

Agricultural serving cooperative carries out organization of stocking and distribution of milk at a certain rural territory, which is a part of the raw area for one or several processing enterprises (private-corporative or cooperative type). Members of such a cooperative are often owners of small family farms. Cooperative is created with the purpose of increasing the level of prosperity of each member by improving the quality of improving milk quality and increasing its production, which can be achieved by improving cow productivity and increase in their amount. The cooperative carries out its commercial activity in the field of rendering services aimed at the increase of milk productive effectiveness, organization of its stocking and distribution.

The main demands towards the quality, stocking and transportation of milk are the following: maximal temperature of milk; stocking/transportation packing to the destination of handing over; sequence of defining the amount (weighing) and quality control; signing handing-reception documents and so on.

At that the business process of "transportation" in the cooperative milk supply chain is manifested in two aspects: internal (connected with a small distance of transportation, mainly in the system of manufacturing logistics) and external (it is carried out for long distances between different organizations or distant subdivisions of an enterprise, mainly in the system of logistics of supply and distribution).

For organizing milk collection in rural areas (settlements of one or several village halls), as a rule, several powerful cooperative milk-receiving (milk collecting) stations are formed. At the same time if the distance towards such stations is huge, additional milk-collecting stations (mini-coolers) are organized which are located, as a rule, in free premises or village courtyards. At that organization of collecting milk by automobile vehicles for its delivery to central milk receiving stations with further transportation to the processing enterprise is carried out.

Thus for the serving cooperative there is a need for effective logistical organization of internal transportation of milk raw materials. business:

At that the process of carrying out such a task may be viewed at two stages (levels) of the milk cooperative

I - creation (projection) of a model of a cooperative on milk gathering inside the optimal radius of exploitation and serving for its potential members (clients) - producers;

II - optimization of routes of internal transportation of milk raw materials in the formed model of the serving cooperative.

For solving this task on I and II stages it has been suggested to apply the general methodology of the SCORmodeling. Besides on the I stage it is reasonable to additionally use the method of linear distribution of limited resources, and on the II - method of the transportation task and a task of a commercial traveller.

I stage (phase)

Setting variable tasks. The collection of milk by a cooperative can be carried out in $n$ settlements or collecting stations. The maximal possible amount of milk stocking in $i$-settlement (collection station) equals $D_{i}(i=\overline{1, n})$. Holding 
capacity of the futuristic cooperative which enable the cooperative to simultaneously store milk have the maximal possible capacity V. The average capacity of milk tank trucks which are due to be bought (rented) for milk transportation equals $Q$

We will denote $N$ as multiple indices of those milk producers - potential members of the cooperative who have agreed to the milk supply. Besides that will be carried out under the condition that the amount of milk will not be less than a certain limit, in this case the lowest limit of milk collecting in $i$-settlement (collection station) equals $d_{i}(i \in N)$.

We will denote $x_{i j}$ - prognostic maximal one-time amount of milk collecting in $i$-settlement $(i=\overline{1, n})$ while passing through $j$-route $(j=\overline{1, k})$.

Thus, the unknown data create the matrix $M$ with the size $n \times k$.

$$
M=\left(\begin{array}{cccccc}
x_{11} & x_{12} & \ldots & x_{1 j} & \ldots & x_{1 k} \\
x_{21} & x_{22} & \ldots & x_{2 j} & \ldots & x_{2 k} \\
\ldots & \ldots & \ldots & \ldots & \ldots & \ldots \\
x_{i 1} & x_{i 2} & \ldots & x_{i j} & \ldots & x_{i k} \\
\ldots & \ldots & \ldots & \ldots & \ldots & \ldots \\
x_{n 1} & x_{n 2} & \ldots & x_{n j} & \ldots & x_{n k}
\end{array}\right)
$$

System of task limitations. The process of milk stocking by a serving cooperative is always connected to maximal and minimal limitations concerning the amount. In particular the minimal possible amount of stocking may depend upon certain contract liabilities or their prospects with milk-processing enterprises, economically grounded break-even point and so on. Limitations concerning maximal possible amount of stocking are initially connected to the potential quantity and production capabilities of cooperative members in certain rural areas.

At that separate prospects of expanding a farm business and existing preconditions for increasing the productivity of the milk herd.

So, the first limitation concerning minimal volumes of milk stocking by a serving cooperative is:

$\sum_{i=1}^{n} \sum_{j=1}^{k} x_{i j} \geq V$

The second limitation concerning maximal possible milk stocking within settlements (collecting stations):

$$
\sum_{j=1}^{k} x_{i j} \leq D_{i}(i=\overline{1, n)}
$$

While establishing the milk serving cooperative it is essential to optimize amount and quantity of assets (milk tank trucks, mini-freezers, milk reception stations and so on). It is necessary to estimate maximally possible for cooperatives amount of assets, importance of radius grounding of members of the cooperation and to define the quantity of optimal milk raw materials collecting routes.

The limitations concerning the latter should include possible different capacity of milk tank trucks, which might be bought or rented by the serving cooperative. At that in case of limiting maximal total quantity of vehicles it is reasonable to focus on average milk tank truck capacity.

Therefore the third limitation concerning the level of infilling milk tank trucks of the cooperative while transporting milk by the route:

$$
\sum_{i=1}^{n} x_{i j} \geq Q_{j}(j=\overline{1, k)}
$$

And the fourth limitation concerning total purchasing (renting) of milk tank trucks for the future cooperative is:

$$
\sum_{i=1}^{n} \sum_{j=1}^{k} x_{i j} \leq k Q
$$

where $Q$ - average capacity of one milk tank truck, tons; $k$ - maximal possible number of milk tank trucks, units. The fifth limitation concerning the number of milk collecting routes is:

$$
\sum_{i=1}^{n} x_{i j} \leq Q_{j}(j=\overline{1, k)}
$$

Thus total amount of one-time milk collecting on a certain route should not increase the individual capacity of a milk tank truck, which will serve this route.

If in the serving cooperative mini milk tank trucks are used without refrigerators, it is essential to limit the time for the process of collecting and transporting milk, as a perishable good, to the central milk collecting station. Such duration 
must be reflected in the limitation as a cumulative index of additional for transportation using circle routes to another settlement or collection station as well as returning to the central milk collecting station. It also might be the maximal average duration of the collecting process and transportation of milk on a separate circle route.

In this case the sixth limitation concerning maximal average duration of the process of milk collecting and milk transportation on $j$-circle route between settlements (collection stations):

$$
\sum_{i=1}^{n} \gamma_{i}^{j} x_{i j} \geq \gamma_{0}^{j} \sum_{i=1}^{n} x_{i j}(j=\overline{1, k)}
$$

or after transformations

$$
\sum_{i=1}^{n}\left(\gamma_{i}^{j}-\gamma_{0}^{j}\right) x_{i j} \geq 0(j=\overline{1, k)}
$$

where $\gamma_{i}^{j}$ - probability that average duration of the milk collection and transportation on $j$-circle route does not exceed the necessary limit, $\gamma_{0}^{j}$ - granted averaged probability.

In separate cases maximal distance of the circle detour by one milk tank truck might also be limited. It can be caused by carrying out benchmarking or the set practice according to results of SCOR-modeling, which define a certain range of effectiveness depending upon distances of internal transportation of the milk raw materials. Thus in limitations it is reasonable to take into consideration the additional distance of detour connected to a certain settlement or milk collection station as well as a total number of milk tank trucks in the serving cooperative. In conclusion average maximal distance of the circle detour will be limited by one milk tank truck. Hence maximal average distance between settlements (collection stations) on a certain circle route might also be limited.

The corresponding seventh limitation concerning the maximal average distance between settlements (collection stations) on $j$-circle route is:

$$
\sum_{i=1}^{n} \mu_{i}^{j} x_{i j} \geq \mu_{0}^{j} \sum_{i=1}^{n} x_{i j}(j=\overline{1, k)}
$$

or after transformations

$$
\sum_{i=1}^{n}\left(\mu_{i}^{j}-\mu_{0}^{j}\right) x_{i j} \geq 0(j=\overline{1, k)}
$$

where $\mu_{i}^{j}$ - probability that maximal average distance between settlements (collection stations) on $j$-circle route does not exceed the necessary limit, $\mu_{0}^{j}$ - granted averaged probability.

The practice of many countries testifies that organization of milk serving cooperative in certain rural areas may be insufficiently effective due to a small number of participants of the cooperation, significant distances for detours as well as low volumes of milk raw materials stocking in certain collection stations especially in combination with distant locations of the latter.

Based on that consideration of such factors in the process of SCOR-modeling and logistical optimization of operations concerning transportation milk raw materials from the supplier's suppliers directly to the supplier itself is crucial.

To a certain extent the mentioned phenomenon in agrarian cooperation is connected with the economical law of the effect of scale of production. As it is well known for effective scaling of production (business) in economics is limited, which is caused by the increase of level of maximal costs and correspondingly total costs of goods, works and services (Abraham, 2013).

At that the change of costs has relatively different character: proportional (costs vary in approximately equal proportions as producing volumes), progressive (costs vary in a relatively bigger proportion than producing volumes) and digressive (costs vary in a relatively smaller proportion than producing volumes).

While projecting milk serving cooperative and defining the radius of its serving it is essential to consider the ratio of increase between additional amounts of milk stocking in a certain collection station and additional costs for its transportation.

In a similar manner the ration with the changes of production volumes is proportional, progressive and digressive cause costs for both internal milk raw materials transportation in comparison with the changes of amounts of its stocking by a serving cooperative.

At that the long progressive character of variable transportation costs and vice versa digressive character of amounts of milk storing may lead to critically high cost of services for members of the servicing cooperative. In such conditions the cooperative alternative of transportation-logistical provision of the process of milk production for households and farms may lose its competitiveness and economic value. 
Accordingly flexibility and adaptability of a part of the milk cooperative chain, in context with SCOR-modeling, may be regulated by limiting the minimal level of ratio of increase in additional volumes of stocking raw materials and additional transportation cost for its collecting. It will enable a cooperative to rationally use benefits of scale of serving of milk producers in certain rural areas, and correspondingly limit the action of a negative effect of such serving (in particular, critical progressive growth of transportation costs).

Hence the eighth limitation concerning the level of ration of growth in amounts of milk stocking and expenses for its transportation (maximal acceptable level of a digressive type of expanding the process of milk stocking compared to transportation costs for it):

$$
\sum_{i=1}^{n} \sum_{j=1}^{k} \frac{\Delta x_{i j}}{\Delta L_{i j}} \geq \beta
$$

where $L$ - costs for moving (transportation) to the following settlement, money units;

$\beta$ - maximal acceptable level of digressive coefficient in amounts of milk stocking in collection stations in comparison with transportation costs.

The ninth limitation concerning carrying out certain conditions of some suppliers or milk processing enterprises by the serving cooperative:

$$
\sum_{i=1}^{n} \sum_{j=1}^{k} x_{i j} \geq W_{1}
$$

The tenth limitation concerning non-negative variables:

$$
x_{i j} \geq 0(i=\overline{1, n} ; j=\overline{1, k})
$$

as well as other possible limitations.

Setting a efficiency function of a task. We consider criterion of optimality as the minimal value of maximally possible constant of changeable transportation costs for all kinds of transportation.

$$
F=\sum_{i=1}^{n} \sum_{j=1}^{k} z_{i j} x_{i j} \rightarrow \min
$$
route.

Here ${ }^{z_{i j}}$ means transportation costs per 1 weight unit of milk brought from $i$-settlement (collection station) using $j$ -

They are maximal possible because in case of not including into the optimal decision of one or another settlement (collection station), factual transportation costs will be decreased due to partial correction of separate routes (so-called "shortcut" transportation).

II stage (phase)

Setting a transportation task. For example an agricultural serving milk cooperative has 15 mini-refrigerators for collecting milk which are located in 10 settlements with significant territorial dispersion and the cooperative has 4 milk tank trucks for transporting milk raw materials to 2 central milk collecting stations of the cooperative.

Maximal possible amounts of one-time transportation of raw materials by one milk tank truck are known: $I-1.5$ tons (petrol fuel system); II - 2 tons (gas fuel system); III - 1.5 tons (diesel fuel system); IV - 1 ton (petrol fuel system).

Also maximal possible one-time amounts of milk stocking are known in 15 collection stations which are located in 10 settlements.

Transportation costs of one ton of milk raw materials by each milk tank truck are different for each collection

\begin{tabular}{|c|c|c|c|c|c|c|c|c|c|c|c|c|c|c|c|}
\hline \multirow{2}{*}{$\begin{array}{c}\text { Milk tank } \\
\text { truck }\end{array}$} & \multicolumn{15}{|c|}{ Milk collection station } \\
\hline & 1 & 2 & 3 & 4 & 5 & 6 & 7 & 8 & 9 & 10 & 11 & 12 & 13 & 14 & 15 \\
\hline 1 & Z1.1 & $\mathrm{Z1.2}$ & Z1.3 & Z1.4 & Z1.5 & Z1.6 & Z1.7 & Z1.8 & Z1.9 & Z1.10 & Z1.11 & Z1.12 & Z1.13 & Z1.14 & Z1.15 \\
\hline II & Z2.1 & Z2.2 & Z2.3 & Z2.4 & Z2.5 & Z2.6 & Z2.7 & Z2.8 & $\mathrm{Z2.9}$ & Z2.10 & Z2.11 & Z2.12 & Z2.13 & Z2.14 & Z2.15 \\
\hline III & Z3.1 & $\mathrm{Z3.2}$ & Z3.3 & 23.4 & Z3.5 & Z3.6 & Z3.7 & Z3.8 & Z3.9 & Z3.10 & Z3.11 & Z3.12 & Z3.13 & Z3.14 & Z3.15 \\
\hline IV & Z4.1 & Z4.2 & Z4.3 & Z4.4 & Z4.5 & Z4.6 & Z4.7 & Z4.8 & Z4.9 & Z4.10 & Z4.11 & Z4.12 & Z4.13 & Z4.14 & Z4.15 \\
\hline
\end{tabular}
station.

Table 1: Maximal ${ }^{\star}$ possible additional variable expenses for transportation of one ton of raw materials by a milk tank truck to central milk collecting stations of the cooperative with successive circle ${ }^{* *}$ route, money units

Note: * - they are maximal because in case of not falling into the optimal solution of the route for one or another collection station, actual transportation costs may decrease due to partial correction of the transportation route (so called "shortcut" transportation).

** additional expenses for moving from place of milk tank truck's departing to each possible collection station as the first and from each possible collection station as the last to the milk reception station should correspond to average radius of serving and these costs should be included into costs for all collection stations as a secure reserve. 
It is necessary to assemble such a plan of milk transportation by vehicles to central milk accepting stations of the cooperative, which will correspond to maximal possible volumes of one-time transportation of raw materials by one milk tank truck and maximal possible one-time volumes of milk stocking within collection stations and provide minimal costs of internal transportation of milk raw materials in the cooperative.

Setting variable tasks. The sought for variables will be amounts of milk raw materials transportation to central milk accepting station in $i$-milk tank truck from $j$-collection station. Correspondingly: variable $i$ - from 1 to 4 ; variable $j-$ from 1 to 15.

Thus in fact it is necessary to define 4 optimal routes for milk collecting be the serving cooperative.

$x_{i j}$ - predicted maximal one-time amount of milk collecting in $i$-collection station $(i=\overline{1, n})$ while passing through $j$ route $(j=\overline{1, k})$.

System of task limitations. Amounts of one-time milk stocking by members of the cooperative in all collection stations exceed maximal possible amounts of one-time raw materials transportation by one milk tank truck, therefore inequalities should be among limitations.

The first group of limitations - limitations concerning maximal possible amounts of one-time raw materials transportation by one milk tank truck.

$$
\sum_{j=1}^{k} x_{i j} \leq D_{i}(i=\overline{1, n})
$$

It implies that milk stocking will be bigger than milk tank trucks can hold. Hence we have an option to choose from all possible collection stations for a certain route only those which are most profitable in accordance with transportation costs. Since milk tank trucks must be filled up we have some limitations.

The second group of limitations - limitations concerning maximal possible one-time amounts of milk stocking within $n$ collection stations, estimated for $k$ milk uank trucks

$$
\sum_{i=1}^{n} x_{i j} \geq Q_{j}(j=\overline{1, k})
$$

Setting the efficiency function. We consider optimal criteria to be the minimal value of total transportation costs for all internal milk transportation.

$$
F=\sum_{i=1}^{n} \sum_{j=1}^{k} z_{i j} x_{i j} \rightarrow \min
$$
route.

Here $z_{i j}$ means that transportation cost per 1 weight unit of milk while transporting from $i$-collection station using $j$ -

At that if we have the condition to stock all milk and it will be enough to fill all milk tank trucks, we will get the close model of a transportation task, if not all milk tank trucks are filled, the system will be open.

Upon solving this transportation task, multitude of collection stations will be divided into 4 sub-multitudes, and it is desirable to develop the most exact optimal transportation route for each of them. It can be achieved using additional solution of the task by a commercial traveler.

According to the conditions it is necessary to create a transportation route through a multitude of settlements (collection stations), distance between them is known, so that the milk tank truck visits each collection station only once to provide minimal route length with returning to the initial place of the route. Hence for each milk tank truck it is necessary to choose the shortest route.

This task may be set as a task of integer-valued linear programming.

$$
\begin{gathered}
\sum_{i=1}^{n} \sum_{j=1}^{n} l_{i j} x_{i j} \rightarrow \min \\
\sum_{j=1}^{n} x_{i j}=1, i=\overline{1, n} \\
\sum_{i=1}^{n} x_{i j}=1, j=\overline{1, n}
\end{gathered}
$$

Values of variables $x_{i j}=1$, if the cycle includes moving from $i$-settlement to $j$-settlement, $x_{i j}=0$, if no.

The indices of estimation of a functional supply chain in the system SCOR-modeling are divided into two groups: I - indices of chain functioning (Performance Attributes) and II - metrics (Metrics).

At that logistical optimization of internal transportation of the milk serving cooperative with the help of the method of linear programming is oriented on both these groups (Table 2). 
Table 2: Separate components of the SCOR-model parameters concerning effectiveness of link functioning in the cooperative milk chain in the process of logistical optimization

\begin{tabular}{|c|c|c|}
\hline \multicolumn{2}{|c|}{$\begin{array}{l}\text { Group of parameters of link functioning } \\
\text { (SCOR-model) }\end{array}$} & $\begin{array}{l}\text { Component of the model of logistical optimization } \\
\text { (I level of metrics in SCOR-model) }\end{array}$ \\
\hline \multirow[b]{3}{*}{ 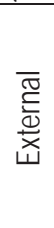 } & Reliability & Volume of milk raw materials of a necessary amount to a necessary place \\
\hline & Speed of response & Limited duration of order cycle completion for milk transportation \\
\hline & Maneuverability (dynamic) & $\begin{array}{l}\text { Flexibility and adaptability of the supply chain due to limitations in level of } \\
\text { regressive amounts of milk stocking in collection stations (at the stage of } \\
\text { establishing a cooperative and at the stage of its functioning while estimating } \\
\text { expediency of widening radius of service) }\end{array}$ \\
\hline \multirow{2}{*}{ 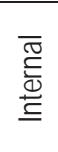 } & Expenses & $\begin{array}{l}\text { Efficiency function of a model - minimal expenses of the serving cooperative per } \\
\text { unit of milk raw materials stocking }\end{array}$ \\
\hline & Assets & $\begin{array}{l}\text { Flow of cooperative assets (mini-refrigerators, milk tank trucks, milk collecting } \\
\text { stations and so on) }\end{array}$ \\
\hline
\end{tabular}

Source: author's development

I group if indices - grouped metrics, which are used for setting directions for strategy of the supply chain. Indices of the functional chain in its turn can be conditionally divided into two subgroups: external (oriented on a client) and internal (oriented on a business process of a focus company). Directly these indices cannot be measured, with its help only directions of strategy are defined. Such indices are: reliability of the supply, response in the supply chain (duration of logistical cycles), maneuverability (dynamics), expenses and effectiveness of asset management.

At the same time II group is a system of the measuring indices which are meant for estimation of the possibility to achieve strategic solutions, defined in the indices chain functioning. It is a set standard for estimation of activity or a process (SCC, 2012).

Integration of SCOR-modeling and logistical concept of management in the SCM system implies effective realization of tasks concerning achieving separate component parameters of the activity or the process.

In particular the suggested logistical model of optimization of internal milk raw materials transportation in the serving cooperative is oriented on co-provision for achieving high values of separate indicators of the first level of metrics (KPI - Key Performance Indicator), i.e. indices which diagnose the general condition of the supply chain.

\section{Conclusions}

The supply chain in the milk business may obtain certain features depending upon its organization and management. It is possible to distinguish such main types of the chain as private-corporative, cooperative and mixed. In the process of the cooperative milk supply chain management it is reasonable to use integrated approach in application of different methodological means which lead to amplification of synergic effect of its influence on objects of management. In particular, this effect may be achieved using a way of integrating concepts/technologies of SCOR-modeling (reengineering of business processes, benchmarking and application of the best practice) with logistical concept/technology of management. At that the logistical concept/technology of management is an approach to management but not its object and it is grounded on principles of rationalistic logistics.

SCOR-modeling and logistical optimization of internal transportation of the milk cooperative is carried out at the level: "supplier's supplier - supplier" or "milk producer - cooperative". Logistical optimization of internal transportation of milk raw resources by the serving cooperative may be separately considered at two stages: I - creation (projecting) and II - functioning of the cooperative. For that it is reasonable to use the integrated methodology of SCOR-modeling and linear programming (logistical-transportation task).

Limitations of logistical optimization are focused on the maintenance in achieving a high level of component parameters of the SCOR-model concerning effectiveness of link functioning in the cooperative milk chain (level of metrics).

In limitations of such a mathematical model on the I stage one must obligatory consider a possible negative effect from using additional collecting stations with a low level of milk stocking (digressive change) and a high level of additional transportation costs (progressive change). Such an approach enables us to optimize the radius of attraction and serving members of the future cooperative as well as to correct this radius in case of changes of separate conditions for the already existing cooperative. 
Taking into account the level of influence on the effectiveness of cooperative activity, it is reasonable to focus on both individualized or exact parameters (for factors of significant influence) and on averaged or range parameters (for factors of insignificant influence) in the limited models on I and II stages. Among the latter factors there may be such parameters ad: average capacity of the milk tank truck, average level of digressiveness of milk stocking amounts, maximal possible costs for a circle detour and so on.

Meaning for theory: theory of integrated application (combination) of different concepts/technologies of management in separate links of the milk supply chain has found further development; mechanism and methodology of logistical optimization of internal transportation of the milk cooperative oriented on metrics of the SCOR-model have been widened and expanded.

Meaning for practice: the suggested methods and developed models can be used in conditions of level planning of average precision during creation (projecting) of a milk cooperative as well in the system of the management in the existing cooperative.

Further researches are reasonable to be focused on searching for ways and principles of the integrated application of SCOR-modeling and means of logistical optimization for different links of the cooperative milk supply chain.

\section{References}

Aramyan, L., Ondersteijn, C., Van Kooten, O., \& Lansink, A. O. (2006). Performance indicators in agri-food production chains. In C. Ondersteijn, J. Wijnands, R. Huirne \& O. Kooten (Eds.), Quantifying the agri-food supply chain (pp. 49-66). The Netherlands: Springer.

Dong, L., \& O'Brien, C. (1999). Integrated decision modelling of supply chain efficiency. International Journal of Production Economics, 59, 147-157.

Li, L., Su, Q. \& Chen, X. (2011). Ensuring supply chain quality performance through applying the SCOR model. International Journal of Production Research, 49, 33-57.

Moazzam, M., Garnevska, E., \& Marr, N. (2012). Benchmarking Agri-food Supply Chain Networks: A Conceptual Framework. World Business Capability Congress. Driving Excellence Innovation Productivity Export Growth, 5-7 December 2012. Auckland, New Zealand.

Krievina, A. (2010). Milk Price Distribution and Factors in Value Adding Chain. Economic Science for Rural Development, $21,116-122$.

Shadbolt, N. (2009). DairyBase: Building a best practice benchmarking system. In L. Jack (Ed.), Benchmarking in food and farming: Creating sustainable change. Surrey, UK: Gower.

Sharma, M., Patel, H., \& Patel, J. (2008). Dudhsagar Dairy: Excelling through Logistics Practices. Retrieved from http://gfjmr.gnu.ac.in/ UserFiles/File/MC1.pdf.

Tariq, M., Mustafa, M. I., Iqbal, A., \& Nawaz, H. (2008). Milk Marketing and Value Chain Constraints. Pakistan Journal of Agricultural Sciences 45,195-200.

Vaněček, D., \& Toušek, R. (2006). Improvement of logistics in milk processing enterprise madeta, inc. in České Budějovice (Czech Republic). Journal of Central European Agriculture, 7(4), 637-642.

Zia, U. (2009). Pakistan: A Dairy Sector at a Crossroads. In N. Morgan (Ed.), Smallholder Dairy Development: Lessons Learned in Asia. Bangkok: Thialand.

Claassen, G. D. H., \& Hendriks, T. H. B. (2007). An application of special ordered sets to a periodic milk collection problem. European Journal of Operational Research, 180(2), 754-769.

Dayarian, I., Crainic, T. G., Gendreau, M., \& Rei, W. (2013). A branch-and-price approach for a multi-period vehicle routing problem. Technical Report CIRRELT-2013-60. Montreal: CIRRELT.

Dayarian, I. (2014). Tactical Vehicle Routing Planning with Application to Milk Collection and Distribution. Electronic Thesis or Doctoral Dissertation. Universit'e de Montr'eal. Retrieved from https://papyrus.bib.umontreal.ca/xmlui/handle/1866/10802.

Du, T., Wang, F. K., \& Lu, P. (2007). A real-time vehicle-dispatching system for consolidating milk runs. Transportation Research Part E, 43, 565-577.

Dooley, A. E., Parker, W. J., \& Blair, H. T. (2005). Modelling of transport costs and logistics for on-farm milk segregation in New Zealand dairying. Computers and Electronics in Agriculture, 48(2), 75-91.

Hoff, A., \& Lokketangen, A. (2007). A tabu search approach for milk collection in western Norway using trucks and trailers. In Proceedings of the Sixth Triennial Symposium Transportation Anal. TRISTAN VI. Phuket Island, Thailand, 10-15 June 2007.

Hui, J. M., \& Jing, W. (2012). Milk-Run Vehicle Routing Optimization Model and Algorithm of Automobile Parts. Applied Mechanics and Materials, 1463, 253-255.

Jafari-Eskandari, M., Jalali-Naiini, S. G. H., Aliahmadi, A. R., \& Sadjadi, S. J. (2010). A Robust Optimization Approach for the Milk Run Problem with Time Windows under Inventory Uncertainty - An Auto Industry Supply Chain Case Study. Proceedings of the 2010 International Conference on Industrial Engineering and Operations Management (pp. 1-7). Dhaka, Bangladesh, January 9-10, 2010.

Lahrichi, N., Crainic, T. G., Gendreau, M., Rei, W., \& Rousseau, L-M. (2012). Strategic analysis of the dairy transportation problem. Technical Report CIRRELT-2012-80, Montreal. Montreal, Forthcoming in Journal of Operational Research Society, CIRRELT, 
2012.

Lobo, D. S., Oliveira, H., Martins, R. S., Rocha Júnior, W. F., Martins, P., \& Yamaguchi, L. C. T. (2004). Logística de transporte na coleta de leite: instrumento para gestão em uma cooperativa agropecuária brasileira, XVIII ANPET. Florianópolis.

Martins, R. S., Lobo, D. S., Rocha Júnior, W. F. D., Oliveira, H., Martins, P., \& Yamaguchi, L. C. T. (2004). Development of a logistic tool to optimized the milk supply of an agricutural cooperative. Gestão \& Produção, 11(3)6 429-440.

Martins, R. S., Oliveira, H., Lobo, D. S., Rocha Júnior, W. F., Martins, P., \& Yamaguchi, L. C. T. (2003). Operations planning and strategy of milk collection: developing a process for optimization. Retrieved from http://id18801.cepead.face.ufmg.br/files/ nucleos/nipe_log/Artigo1.pdf.

Sadjadi, S. J., Jafari, M., \& Amini, T. (2009). A new mathematical modeling and a genetic algorithm search for milk run problem (an auto industry supply chain case study). International Journal of Advanced Manufacturing Technologies, 44(1-2), 194-200.

Supply Chain Council (2012). Supply chain operations reference (SCOR) model: Overview version 10.

Velychko, O. (2014). Development of infrastructural objects of providing logistics in the system of storing plant cultivation produce. Ekonomichnyi chasopys-XXI, 1-2(1), 110-113.

Abraham, R., \& Harrington, C. (2013). Measuring Profit in Cooperatives: Definition and Methods. International Journal of Business, Humanities and Technology, 3(4), 21-33. 